\title{
FLOWS: MODELO DE INOVAÇÃO COM BASE EM DESIGN A PARTIR DE RESÍDUOS SÓLIDOS
}

\author{
CLÁUDIO PEREIRA DE SAMPAIO, DR. | UEL \\ SUZANA BARRETO MARTINS, DRA. | UEL \\ FERNANDO ANTÔNIO CARNEIRO MOREIRA DA SILVA | FA.ULISBOA \\ RITA ASSOREIRA ALMENDRA, DRA. | FA.ULISBOA
}

A presente tese de doutorado foi desenvolvida no contexto de um projeto de pesquisa (2012-2015) conduzido pelo grupo de pesquisa "Design, Sustentabilidade e Inovação (DeSIn)", do Departamento de Design da Universidade Estadual de Londrina (UEL), o qual teve por objetivo investigar e desenvolver alternativas para a questão do descarte inadequado de resíduos têxteis sintéticos.

A participação em projetos de pesquisa na UEL entre 2010 e 2016 permitiu ao autor construir uma visão ampliada da problemática relacionada aos resíduos têxteis sintéticos, notadamente aqueles produzidos pelas indústrias do setor de vestuário da cidade de Londrina e região, no norte do Paraná. Esta visão foi potencializada pela experiência anteriormente obtida como pesquisador do Núcleo de Design e Sustentabilidade da Universidade Federal do Paraná (NDS--UFPR), onde o autor participou de 2004 a 2010 de diversas atividades de Pesquisa e Desenvolvimento (P\&D) em design aplicado a diversos tipos de resíduos.

Com base nestes doze anos de pesquisa em design aplicado a resíduos, o autor percebeu uma constante dificuldade no modo de planejar e gerir os projetos e equipes. Além disso, no caso dos resíduos têxteis, o autor verificou uma ênfase em soluções de caráter artesanal, com evidentes limitações em termos de alcance, dada a quantidade de resíduo gerado.

Ao mesmo tempo, percebeu uma dificuldade frequente em se buscar soluções que envolvam uma complexidade científica e tecnológica maior, implicando na necessidade de atuação interdisciplinar.

No caso das equipes de P\&D, as dificuldades percebidas vão desde o modo de organizar e gerir a equipe até formas de motivar e premiar os investigadores, entre vários outros desafios. Tais vivências serviram, portanto, como estímulos iniciais para esta tese, que buscou dar uma resposta convincente às dificuldades ora relatadas.

Assim, esta tese insere-se na área do design enquanto forma de solução de problemas com base em interdisciplinaridade, criatividade, empatia e experimentação (design thinking), tendo o usuário como ponto de partida e centro de atenção, e nas suas inter-relações com as áreas da química, engenharia de materiais e engenharia têxtil, e de negócios.

Esta pesquisa teve como premissas:

- A sustentabilidade ambiental, considerando todo o ciclo de vida de materiais, produtos, serviços e sistemas, por meio da aproximação com a química e da engenharia de materiais, considerando a abordagem integrada da química verde, engenharia verde e design verde (ou ecodesign);

- A busca pela criação de valor, motivo pelo qual o design relaciona-se com o conceito de inovação;

- A eficácia e eficiência da equipe de P\&D, considerando todo o processo, atividades e aspectos relacionados ao trabalho da equipe.

Como resultado, foi sistematizado um modelo de gestão da equipe e do processo de P\&D, complementado por uma metodologia que inclui métodos e ferramentas necessários à sua operacionalização.

Cabe ressaltar que, embora os resíduos têxteis sintéticos sejam o ponto de partida da pesquisa, prevê-se que o modelo e metodologia resultantes desta tese possam ser aplicáveis ao processo de P\&D em novos materiais também para outros tipos de resíduos, ampliando assim seu potencial de utilização. Utilizou-se, portanto, uma abordagem indutiva de pesquisa, buscando-se uma aplicação mais geral a partir de um caso particular.

Para a realização desta investigação, utilizou-se uma abordagem metodológica exploratória, composta por 
métodos intervencionistas e não-intervencionistas de investigação, e de caráter basicamente qualitativo. $\mathrm{O}$ levantamento do estado da arte foi feito por meio de revisão crítica de literatura e entrevistas semiestruturadas, e a pesquisa empírica, por meio de pesquisa-ação junto a um grupo de P\&D (grupo DeSIn, liderado pelo autor).

O aprendizado obtido na pesquisa-ação serviu de referência para a construção de um modelo metodológico, o qual foi avaliado por meio de estudo comparativo entre dois grupos de amostra e dois de controle, que utilizaram o modelo em um projeto prático, além de outros doze grupos de avaliação adicionais, oriundos de três universidades distintas (UEL, UTFPR Apucarana e Universidade do Minho/Portugal).

Os resultados possibilitaram correções no modelo inicial, bem como uma verificação sobre a validade dos pressupostos iniciais da investigação. O resultado final denomina-se "FLOWS - Modelo Integrado de P\&D em Resíduos Sólidos", o qual é apresentado na íntegra no Volume 2 da tese aqui citada.

\section{O MODELO METODOLÓGICO: FLOWS}

O Modelo FLOWS consiste de uma metodologia orientada pelo design, e que por isso integra tanto as variáveis
Cada um dos módulos foi elaborado a partir de questões essenciais com as quais um gestor de P\&D se depara, as quais direcionam o uso de conjuntos de ferramentas específicos (toolboxes).

Considerando-se o objetivo de alcançar o público para o qual o modelo foi desenvolvido (pesquisadores e agentes de inovação, tanto em universidades e centros de pesquisa quanto nas empresas), o modelo foi disponibilizado de forma integral em um website (flows.brouhaus. com.br), desenvolvido de forma responsiva para possibilitar o uso também em dispositivos móveis. uma abordagem ao mesmo tempo humanista, criativa, técnica, planejadora e integradora. O modelo é estruturado em cinco partes (módulos) principais (Figura 1): Planejamento, Equipe, Liderança, Processo e Produtos (Inovações, Conhecimento e Aprendizagem). Estes módulos derivam da abordagem de Cross (1982), que propõe uma abordagem de estudo do design com base em três elementos principais - Pessoas (aqui abordadas como Equipe e Liderança), Processos e Produtos - e à qual foi acrescentado o Planejamento de Projeto.

Cada um dos cinco módulos do modelo FLOWS é organizado em um conjunto específico de etapas, cada uma com seus respectivos conjuntos de ferramentas e métodos (toolboxes) que permitem à equipe de P\&D operacionalizar as atividades ao longo do processo de trabalho. $O$ modelo conta com mais de 170 ferramentas que os gestores de $P \& D$ e suas equipes podem utilizar para planejar $e$ gerir seu trabalho.

Devido ao caráter modular, o modelo pode ser utilizado tanto de forma integral quanto parcial, conforme a necessidade do projeto. Cada ferramenta ou método é apresentada na forma de uma folha única de trabalho (worksheet), a qual traz as informações essenciais para a sua compreensão e uso pelo pesquisador. 